\title{
GLOBALIZAÇÃO E SOBERANIA: A EXCLUSÃO DOS DIREITOS HUMANOS DOS ESTRANGEIROS PELO ESTADO
}

\author{
GLOBALIZATION AND SOVEREIGNTY: THE EXCLUSION OF HUMAN RIGHTS OF \\ FOREIGN STATE
}

Marco Aurélio Pieri Zeferino*
Juventino de Castro Aguado**

\section{Resumo}

Atualmente, com a crise econômica enfrentada por países outrora dominantes, vislumbramos o ressurgimento de ideários estamentais de sobreposição e valorização da soberania nacional frente à crescente movimentação de massas humanas sulistas rumo ao norte da linha equatorial. Trata-se de uma resultante da própria globalização, tendendo à internacionalização social, econômica e cultural, possibilitando um maior fluxo de pessoas. Desta forma, as heterogeneidades e particularidades de cada povo vão se perdendo frente à unificação global, proposta pela "inserção" ou "integração" ideológica presente no conceito de globalização. Na história contemporânea, um grande problema para a efetivação internacional dos direitos humanos reside na soberania e intervenções dos Estados praticadas em arrepio aos princípios humanitários, acrescendo-se a nefasta atuação do poder econômico transnacional, denominada geopoliticamente de "globalização econômica hegemônica". Assim sendo, supramencionada globalização está assente na ideologia monopolista jurídica e científica conferida por alguns países, os quais aliam tecnologia, ciência e capitais como instrumentos de uma nova forma colonial, resultando em uma revolução técnico-científica unilateral e vertical, opondo dominantes e dominados, submetendo-os à prevalência da crença cultural de superioridade científica ocidental, daí excludente, um real eurocentrismo científico monopolista, acrescido ao monopólio estadunidense. Curiosamente, a dominação via globalização cria um neocolonialismo às avessas, visto que milhões de migrantes se dirigem anualmente para o continente europeu, forçando integrações e ocupações que demandam a relativização dos ordenamentos jurídicos internos via princípios e instrumentos presentes no Direito Internacional dos Direitos Humanos, tendentes à persecução de seu finalismo axiológico consubstanciado na defesa da dignidade da pessoa humana.

Palavras-chave: Globalização - soberania - dignidade da pessoa humana.

\footnotetext{
Abstract

Currently, the economic crisis faced by once-dominant countries, we see the resurgence of ideologies estamentais overlap and enhancement of national sovereignty against the growing movement of human masses Southerners northward abyssal equatorial line. This is a result of globalization itself, tending to internationalize social, economic and cultural life, allowing a

* Bolsista pela CAPES. Mestrando em Direitos Coletivos e Cidadania pela Universidade de Ribeirão Preto (Unaerp). Especialista em Gestão Jurídica da Empresa pela Unesp -Franca. Advogado.

** Professor do Programa de Mestrado em Direitos Coletivos e Cidadania da Unaerp/Ribeirão Preto, mestre em Sociologia Política pela Fundação Escola de Sociologia e Política de São Paulo, doutor em História Social pela Universidade de São Paulo, pós-doutor pela Universidade de Coimbra.
} 
greater flow of people. Thus, the heterogeneity and particularities of each people are lost in the face of global unification, proposed by the "insertion" or "integration" in this ideological concept of globalization. In contemporary history, a major problem for the realization of international human rights lies in the sovereignty of states and interventions, many of them in defiance to humanitarian principles, adding to the nefarious activities of transnational economic power, geopolitically called the "hegemonic economic globalization". Thus, globalization is above monopolistic ideology based on legal and scientific, that is, in fact the universal acceptance of a scientific unilateral, a monopoly granted to some countries, which combine technology, science and capital instruments as a new form of colonial, resulting in a scientific-technical revolution unilateral, ie, vertical, opposing rulers and ruled, serving as tools and instruments via submission prevalence of cultural belief of a Western scientific unit, hence excluding a real Eurocentrism scientific monopoly, the monopoly plus U.S.. Interestingly, domination through globalization creates a neo-colonialism in reverse, since millions of foreigners flock every year to the European continent, forcing integrations and occupations, which has been hampered by the dogma of the sovereignty, contributing this work to formulate a more International Humanist and integrative, allowing the relativization of the domestic legal principles and instruments through gifts in International Law of Human Rights, aimed at the pursuit of his axiological finality, ie, the defense of human dignity.

Keywords: Globalization - sovereignty - human dignity.

\section{Introdução}

Pelo viés econômico e geopolítico, o processo globalizante impõe a crescente interdependência das economias nacionais via revolução técnico-científica, cujos investimentos transnacionalizam-se pela ânsia e avidez por lucros instantâneos, capital de certa forma especulativo e fluido quanto à busca de áreas promissoras, a exemplo do Brasil e sua suculenta taxa de juros.

Ademais, a globalização hegemônica atenta contra o ideário de território e fronteira, justificando a invasão de certos Estados "desalinhados" e subdesenvolvidos quanto à nova ordem, por Estados ricos, invasões ideologicamente assentadas sobre o ideário de defesa da paz, a exemplo da Doutrina Bush e sua ingerência no Oriente Médio, cuja sucessão de fatos demonstra tacitamente possíveis interesses econômicos contidos na região, especialmente àqueles referentes às abundantes reservas petrolíferas ali presentes, afigurando-se um "direito universal de intervenção das grandes potências” sem qualquer vocação humanitária. 
Além destas submissões, vislumbramos também, intervenções econômicas, tais como a influência do FMI ao ditar regras internas aos países tomadores de seus créditos, regras as quais acabam minando investimentos em setores sociais importantes como educação e saúde, impossibilitando a adoção do Welfare State; além de presenciarmos as intervenções das grandes corporações transnacionais, monopolizando a produção e os preços no mercado, esfacelando a concorrência via adoção de práticas abusivas e concentracionistas visando tão somente a persecução irracional e insustentável do lucro.

Em conseqüência, presenciam-se efeitos nefastos aos países emergentes, às vezes, subdesenvolvidos, impondo segundo esta lógica, um neocolonialismo vertical, cuja relação dominantes-dominados ocorre através de dois pilares de sustentação: capital e tecnologia, mormente concebidos como novos instrumentos de dominação, bem como a nova divisão internacional do trabalho, que de nova nada possui, muito pelo contrário, os países ricos continuam exportando tecnologias, cabendo aos pobres a exportação de suas matérias primas no intuito de tentarem equilibrar suas balanças comerciais, vendendo suas riquezas a preço vil, além de explorar sua mão de obra barata, quase “descartável”, às custas de prejuízos sociais profundos.

Neste sentido o mundo assiste o progresso econômico da China, crescimento este sustentado pela intermitente exploração de mão de obra barata via instalação de transnacionais favorecidas pelo governo em regiões que funcionam como verdadeiras plataformas de exportação, geopoliticamente concebidas por ZEE’s, Zonas Econômicas Especiais, cuja produção em larga escala conduz seres humanos ao trabalho semi-escravo, exatamente nos moldes da histórica Revolução Industrial.

Portanto, pode-se inferir que tais medidas e conseqüências globalizantes não se mostraram aptas a levar ao desenvolvimento equânime da humanidade, servido tão somente para aprofundar os abismos existentes entre os hemisférios norte e sul, suas grandes diferenças sociais.

Quanto à nova forma de colonização de exploração frente ao eixo norte-sul, verificou-se o aumento das dívidas externas dos países subdesenvolvidos junto ao FMI e ao Banco Mundial, sobretudo na década de 80 devido aos problemas estruturais do sistema, R. Fac. Dir. UFG, v. 38, n. 1, p. 92 - 118, jan. /jun. 2014 
possibilitando a ingerência não consentida junto às soberanias dos países inadimplentes, ocorrendo uma verdadeira "compra da soberania" pelo poder econômico, o qual vem desmantelando qualquer Estado social sob o ideário da liberalização econômica, mediante a desregulamentação do setor financeiro e a privatização das riquezas naturais e dos serviços públicos essenciais, garantindo seus recebíveis mediante cortes em setores de extrema importância social.

Atualmente, contrários a estas imposições, alguns países como a Bolívia, a Venezuela, o Equador e a Argentina optam por nacionalizar recursos e empresas, descumprindo contratos, no intuito de fortalecerem um constitucionalismo social, um certo "welfare state". Infelizmente, sob a ótica geopolítica hegemônica, tais medidas, apesar de populares apresentamse como autodestrutivas, vez que tais países acabam sendo excluídos de quaisquer possibilidades no tocante aos investimentos estrangeiros, sendo consideradas áreas de alto risco para fluxos de capitais externos, devido à insegurança jurídica ali presente. Os efeitos, adversos ao extremo, acabam por minar um crescimento econômico, visto que supramencionada postura nacionalista gera uma estagnação dolosa por parte do poderio econômico, cujos atores internacionais responsáveis pelo fluxo volátil de capitais acabam por ignorar imediatamente, no que se refere ao desenvolvimento de mencionadas áreas.

Ideologicamente, no espectro da globalização, ressalta-se o papel da mídia, a qual, dominada por interesses e capitais estrangeiros, semeia ideais globalizantes via meios de comunicação de massa, como exemplificamente o capitalismo financeiro e o consumo exacerbado no intuito de resguardarem ao "mundo do sul" a qualidade de mercados consumidores cativos e fiéis aos produtos advindos do "mundo do norte", assegurando assim a persecução de lucros provenientes de royalties. Ademais, verificamos o estabelecimento de uma relação de dependência ante a inoperância e o pouco desenvolvimento das indústrias locais, ocasionando um aumento significativo de desempregados, resultando em um imenso contingente de excluídos e explorados, sem quaisquer formas de assistência e amparo pelo Estado.

Devido à realidade utópica de que a globalização nivela o desenvolvimento global de forma equânime a todos os Estados, possibilitando o surgimento de uma democracia global, R. Fac. Dir. UFG, v. 38, n. 1, p. 92 - 118, jan. / jun. 2014 
plural e transparente, torna-se imprescindível a insurgência de ideais imunes a estes valores, eis que, a contrário sensu, a globalização tem apenas aprofundado os problemas sociais junto ao hemisfério sul ${ }^{1}$.

Possivelmente, as únicas alternativas para a adoção de uma democracia global plena decorrem da atuação contínua dos movimentos sociais, combinada com projetos institucionais voltados ao cancelamento da dívida externa de países pobres; democratização das nações unidas, libertação dos povos e trabalhadores e, principalmente, uma maior integração entre os povos, pois somente assim, diminuiríamos o problema global da acumulação de riquezas.

Neste sentido, preceitua Juventino Aguado (2012, p. 25) sobre a importância dos novos atores sociais:

Estamos diante de uma sociedade de contornos visíveis, quase que evidentes, que apresenta um novo cenário onde transformações profundas, mudanças aceleradas, culminam em efeitos de um processo globalizante e, ao mesmo tempo, mais plural, onde os interesses e os poderes dos estados nacionais abrem espaço (ou são forçados a abrir) para o protagonismo de uma diversidade de atores, inclusive não estatais, que se distribuem por todos os campos da vida política, jurídica, econômica, cultural etc. O transnacionalismo, o internacionalismo, a mundialização, o cosmopolitismo, obrigam o interno dos Estados e seus poderes, o seu Direito incluído, a conviver em harmonia com o externo a ele como se fosse uma única realidade.

\section{A Face Reversa do Neoliberalismo Globalizante}

Na mesma dimensão globalizante, a internacionalização mundial tem possibilitado um maior acesso à informação, permitindo um maior conhecimento acerca das diferenças de desenvolvimento e dos padrões de vida presentes nas diversas partes do mundo, possibilitando uma comparação subjetiva entre realidades internas e externas, ou seja, dentro do Estado e entre Estados distintos.

Atualmente, verifica-se que o fenômeno de internacionalização tem fortalecido a circulação internacional de pessoas mediante o enfraquecimento do conceito de território e da soberania estatal. Devido a este enfraquecimento, países desenvolvidos tem sido "invadidos" por

\footnotetext{
${ }^{1}$ A respeito destas idéias, importante a leitura de GIDDENS, Anthony. As Consequências da Modernidade. São
} Paulo: Ed. UNESP, 1991.

R. Fac. Dir. UFG, v. 38, n. 1, p. 92 - 118, jan. /jun. 2014

ISSN 0101-7187 
levas de estrangeiros em busca de melhores condições de vida, movimento que denominaria "colonização às avessas", a exemplo do que vem ocorrendo na França, cuja mão de obra estrangeira proveniente do norte do continente africano vem ocasionando conflitos pelos postos de trabalho existentes, acrescendo-se a isto, o surgimento de conflitos culturais e religiosos, demandando a adoção de leis que restringem a liberdade de expressão exatamente no país celeiro das liberdades individuais. Com a chegada dos estrangeiros, não somente na França, mas em toda a Europa, assistimos uma reversão do neoliberalismo globalizante, ou seja, os ideais liberais contidos nas revoluções europeias, lastreados na trilogia liberdade, igualdade e fraternidade, vem sendo restringidos pela circulação global de pessoas, onde países outrora colonizadores tendem à ser colonizados, ocupados por milhões de estrangeiros provenientes de locais onde a vida tornouse insustentável graças à histórica exploração dos países colonizadores, os quais, agora, mais do que nunca, sentem-se ameaçados pelos novos "colonizadores", estrangeiros, em busca de melhores condições de vida e de um mínimo de dignidade, que um dia, lhe foram tiradas, daí a reversão do neocolonialismo, uma colonização às avessas, processo crescente presente não somente na Europa com os africanos, mas também nos Estados Unidos com os latinos e na Austrália, com imigrantes provenientes de vários países asiáticos e do meio oriente.

É necessário ressaltar que nestes últimos anos, anos de crise na Europa pós-2009, os fluxos imigratórios não somente diminuíram sensivelmente, como, inclusive, iniciaram-se dois processos inversos: muitos dos imigrantes estão retornando aos seus países e europeus dos países mais atingidos pela crise, estão migrando para dentro e fora da Europa.

Contrários ao recebimento de estrangeiros "não selecionados", Estados desenvolvidos vem utilizando a soberania estatal como escudo protetivo à assunção de suas obrigações humanitárias, sendo que aludida questão existe desde os primórdios das guerras mundiais, visto que a temática da soberania dos Estados foi profundamente discutida entre Kelsen, ferrenho defensor juspositivista da supremacia do direito internacional sobre o direito nacional e a soberania, e seu aluno Umberto Campagnolo, sendo que este, ao defender sua tese de doutorado em 1937, aprofundou a idéia da motivação política envolvendo o conceito de soberania e sua superioridade sobre as normas de direito internacional. 
A cognição da filosofia do direito de Campagnolo assinalava o surgimento de uma nova doutrina referentemente ao conflito entre soberania e direito internacional, pugnando pela natureza política e não jurídica do conflito, assentada pela definição de soberania "como autoridade absoluta em relação aos seus sujeitos ou como verdadeira onipotência”.(2002, p.121)

Kelsen (2002, p. 61) contestando Campagnolo, designava como "imperialista a via na qual um Estado impõe a sua vontade sobre a soberania dos outros, contrapondo-se à idéia de federalismo, aceitando a primazia do direito internacional, refutando a expansão da soberania de um único Estado às custas da soberania de outros”.

Verifica-se o contexto histórico entre as discussões de Kelsen e Campagnolo, ou seja, uma Europa entre guerras, cujo imperialismo se fortalecia, visões estatalistas emergiam sob o ódio e a xenofobia desencadeadas pelas humilhantes imposições realizadas pelo Tratado de Versalhes.

A compreensão realista e histórica de Kelsen possibilitou a construção de uma nova teoria:

Dedicado ao tema das relações entre o direito estatal e o direito internacional, ele expunha sua tese célebre, que revirava tanto a teoria monista tradicional da primazia do direito estatal sobre o direito internacional, quanto aquela mais difundida entre os internacionalistas da época, do dualismo entre o direito estatal e o direito internacional, chegando assim a uma tese monista mas de cabeça para baixo, da primazia do direito internacional sobre o direito estatal. Essa afirmação se fundamentava na dupla constatação de que um ordenamento jurídico estatal é válido somente quando é efetivo e que o princípio da efetividade é um princípio próprio do direito internacional, ou seja, é um princípio com base no qual o direito internacional reconhece a existência de um Estado, delimitando não apenas seu âmbito de validade especial e temporal, mas ainda sob certos aspectos, também seu âmbito material. Como consequiência, um Estado, em vez de ser juntamente com outros Estados, o criador do Direito Internacional, deste último é criatura, sendo efetivamente definido como um ordenamento jurídico parcial derivado do direito internacional, ou até mesmo como órgão da comunidade jurídica internacional. (2002, p. 81-82)

A teoria kelseniana conduz à diminuição do imperialismo via ideário da prevalência de uma universalização jurídica. Assim, deveria haver a "negação da atribuição a cada Estado do caráter da soberania, demolida como dogma que serve unicamente de instrumento da ideologia imperialista". (KELSEN, 2002, p. 82) 


\section{A Importância da Relativização do Dogma da Soberania Rígida pelos Direitos Humanos}

Com a relativização fática do conceito de fronteiras, Jürgen Habermas afirma enfaticamente que as fronteiras nacionais tornaram-se "porosas" (para um melhor conhecimento destas ideias, cf. "A Constelação pós-nacional”, vide bibliografia final), sendo que os países desenvolvidos procuram reafirmar sua soberania como forma de rechaçar a entrada de estrangeiros, ou mesmo de realizar a autotutela dos direitos humanos no que se refere à tais coletividades, tornando absoluto o dogma soberano, reduzindo o Estado de tal forma a impedir a assemelhação progressiva entre cidadão e estrangeiro, impossibilitando o surgimento de um Estado universal, um "civitas máxima", servindo os direitos nacionais como instrumentos de opressão, uma verdadeira oposição normativa interna entre Estados e estrangeiros, sob o manto da soberania, absoluta e totalitária.

Acerca da manutenção deste ideário de soberania, discorre Richard Falk (1999, p. 163):

O fundamento estabilizador do moderno mecanismo jurídico é a idéia presente no conceito de soberania nacional de que os governos não estão obrigados a padrões ou procedimentos de responsabilidade externa no tratamento dos seus próprios cidadãos ou de outros que estejam sob o seu controle sem uma expressão oficial de consentimento.

Tais conceitos conduzem a uma soberania "fechada", absolutista, uma relação de autoridade suprema presente no seio do Estado, o que se demonstra insustentável frente à magnitude e importância dos direitos humanos, eis que o direito internacional dos direitos humanos pugna pela universalidade, pela assimilação dos Estados quanto à necessidade de promover ao estrangeiro um status de cidadão, no que se refere à concessão de direitos fundamentais, e antes, é claro, oferecer uma abertura que não dificulte os trâmites de entrada, permanência e trabalho para aqueles que querem e necessitam chegar.

Sob o tema, Piovesan (2006, p. 10-11) afirma a importância de um Constitucionalismo Global, frente à internacionalização evidente de sobreditos direitos:

No esforço de reconstrução dos direitos humanos do Pós-Guerra, há de um lado, a emergência do Direito Internacional dos Direitos Humanos, e, de outro, a emergência da nova feição do Direito Constitucional ocidental aberto a princípios e valores que enfatizam a dignidade da pessoa humana. Vale dizer, no âmbito do Direito Internacional, começa a ser delineado um sistema normativo internacional de proteção dos direitos

R. Fac. Dir. UFG, v. 38, n. 1, p. 92 - 118, jan. / jun. 2014

ISSN 0101-7187 
humanos, projetando a vertente de um constitucionalismo global, vocacionado a proteger direitos fundamentais e a limitar o poder do Estado, mediante a criação de um aparato internacional de proteção de direitos.(grifos nossos)

Portanto, vislumbramos uma corrente favorável à flexibilização do dogma da soberania no que se refere à persecução de garantia mínima à dignidade humana, bem como aos contingentes excluídos, incluindo-se estrangeiros, afigurada a preexistência de grande carga axiológica moral atinente aos direitos humanos.

Nestes termos, presenciam-se nos direitos humanos, cargas morais, visto que são direitos morais, independendo da positivação internacional efetuada pela norma jurídica, daí a aplicabilidade de normas consuetudinárias no que se refere às lacunas existentes. Ademais, possuem natureza de universais em relação aos titulares, não devendo encontrar obstáculos frente aos ordenamentos nacionais, sob pena de configuração de autotutela estatal, já que a soberania não lhes pode ser oponível; sendo direitos preferenciais, visto que a eficácia destes direitos conferem legitimidade ao ordenamento vigente, além de serem fundamentais, abrigando necessidades e carências essenciais aos seres humanos.

Ainda hoje, a internacionalização dos direitos humanos encontra obstáculos frente aos ordenamentos estatais. Entretanto, vem ganhando força o ideário de uma universalização internacionalista que se assenta na multiplicidade de compromissos que a comunidade das nações assume em razão dos vários Tratados, Pactos e Convenções assinados e ratificados pelos Estados.

Sob o enfoque do Direito Internacional, Ramos (2012, p.222) descreve que "cabe analisar se o Estado cumpriu (ou não) seus compromissos internacionais, não aceitando escusas típicas do direito interno, como, por exemplo, superioridade da Constituição sobre os tratados". Este tema, sem dúvida, tem assumido uma situação de crescente polêmica.

\section{Por um Constitucionalismo Global: os Instrumentos do Direito Internacional dos Direitos Humanos}


Diante do exposto acima, cabe propugnar por um constitucionalismo global, onde os valores que tornam viável a dignidade da pessoa humana se tornam confluentes num constitucionalismo nacional incorporando as conquistas do constitucionalismo internacional.

$\mathrm{O}$ respeito aos direitos fundamentais pressupõe o abandono do etnocentrismo, onde há uma ideologia cultural dominante, em geral a cultura própria, ocidental, dentre outras... Tal postura possibilita o reconhecimento de diferenças, de heterogeneidades presentes entre nacionais e estrangeiros, sejam elas culturais, étnicas, sociais, econômicas ou religiosas, fortalecendo um dos primados da dignidade da pessoa humana: a autodeterminação pessoal.

Quando esta liberdade de autodeterminação se manifesta na vontade ou na necessidade de buscar a própria sobrevivência através do ato migratório, o reconhecimento por parte do Estado receptor a este direito cidadão forma parte de uma visão humana e juridicamente difícil de questionar. Estamos pensando numa teoria sobre uma cidadania que seja capaz de converter o conjunto da humanidade numa comunidade baseada na solidariedade em relação à qual ninguém fique excluído. É o que poderíamos identificar como uma cidadania social cosmopolita, o que vale dizer universalizar a cidadania social. (Sobre estas ideias sugerimos a leitura de Adela Cortina, ver na bibliografia final)

Quando se discute e se defende, muito acertadamente, a existência hoje de um constitucionalismo global e de um direito internacional dos Direitos Humanos, em sequência ao constitucionalismo e direito nacionais, está defendendo-se a idéia de que este mundo global é um mundo de todos e para todos. O mar é um só e há somente um barco à disposição de todos.

Neste sentido, o artigo 13 da Declaração Universal dos Direitos do Homem assegura a cada indivíduo a possibilidade de deixar qualquer país, inclusive o seu, podendo a qualquer momento a ele regressar, enquanto que a Carta Africana dos Direitos Humanos e das Pessoas de 1981 propõe em seu artigo 18, que todo indivíduo deve ter o direito de livre locomoção e residência dentro de um Estado. 
Em uma visão jusnaturalista, o próprio direito natural impede que o Estado recuse guarida à vinda de estrangeiros por motivos pacíficos, notadamente àqueles cujos territórios sofreram desastres ambientais, como terremotos, inundações, seca e principalmente a fome, cujo solo estéril conduz contingentes humanos a abandonar seu local de origem, em busca de uma vida melhor, a exemplo do que vem ocorrendo com os deslocados ambientais africanos, ou mesmo em países cujo trabalho impossibilite um mínimo de dignidade existencial. Trata-se de norma insculpida no direito consuetudinário, assegurando-se a liberdade de circulação de pessoas, desvinculando-a do conceito fechado de soberania e território.

Acerca da importância do Estado frente à sociedade constitucional, Tavares Neto discorre acerca da alteridade (2010, p. 31) elencando que "o Estado, como estrutura organizada de poder, desempenha a função de garantir entre os homens uma convivência ordenada de forma harmoniosa e segura, sobretudo a de manter a paz e a segurança jurídica”.

Ainda neste sentido, prossegue Tavares Neto (2010, p. 32) propondo que " a sobrevivência do Direito Constitucional e, mesmo o Constitucionalismo, passa pela assimilação dos direitos humanos como liame, reserva, para a (re) construção da sociabilidade, e isto, numa dimensão local, regional e global".

Há no atual contexto internacional, a necessidade de relativização do conceito de soberania, aliás, ela já está naturalmente relativizada e diminuída diante do impacto da convivência e interdependência entre sociedades e Estados. Isto torna possível a institucionalização e internacionalização dos direitos humanos, desvinculando sua idéia ao conceito de território, ou seja, pela universalidade de aludidos direitos, decorre sua natureza transnacional, extrafronteiras, operando-se a necessidade premente de um transconstitucionalismo global humanitário.

Com referência à histórica alegação jurídica de independência dos Estados, Aguado (2012, p.25-26) assim pondera:

O Estado já não é mais o Estado auto-suficiente que se vale por si mesmo e que decide por si. O Direito, a Constituição estatal, já não estão mais imunes às influências e/ou 
interferências de um supra-constitucionalismo onde o internacional se imiscui no nacional e o global se intromete no local.

Acerca da transnacionalidade presente na era contemporânea, Thelma Cavarzere (1995, p.5) discorre que:

A humanidade a integração do homem no gênero a que pertence, devendo essa integração ser considerada em escala planetária. Assim, o homem pertence à humanidade, independentemente de desejá-lo, sendo ele, além de componente da realidade social que é o direito, o paradigma e a gênese dos valores em que se alicerça toda a ordem jurídica tanto interna como internacional.

Estruturando seu pensamento Cavarzere (1995, p. 38), citando Grotius, sublinha que:

O reconhecido direito de livre circulação possibilitava aos cidadãos fixar-se num território estrangeiro, fosse por razões de necessidade de locomover-se, fosse por qualquer outra causa justa. Segundo ele, o Estado não podia impedir essa fixação vetando a entrada do estrangeiro.

A nova doutrina do Direito Internacional dos Direitos Humanos possui como princípios regentes a universalidade, visto que tais direitos possuem extensão universal, válida para todos, independentemente dos ordenamentos jurídicos e soberanias nacionais, perpassando tais conceitos por situar-se em um plano jusnaturalista, imanente à dignidade da pessoa humana, abarcando um maior número de direitos dada a interdependência com relação à outros direitos, afigurando-os inalienáveis e indivisíveis, eis que a garantia de tais direitos seria condição para a observância de todos os demais, de forma que a violação e o desrespeito à qualquer deles implicaria na violação de uma integralidade de direitos e à própria norma consuetudinária humanista.

Ao mesmo tempo que os Direitos Humanos possuem a característica de universalidade, eles se definem também como indivisíveis, seu conceito é compreensivo e abrangente. Segundo a Resolução n 32/130 da Assembléia Geral das Nações Unidas e reiterada na Declaração de Viena de 1993 no seu $\S 5^{\circ}$, “Todos os direitos humanos constituem um complexo integral, único e indivisível, em que os diferentes direitos estão necessariamente interrelacionados e interdependentes". 
Por isto, além de não ser concebida a dissociação dos direitos civis e políticos dos modernos direitos sociais, econômicos e culturais, também esse conjunto de direitos não está condicionado a peculiaridades culturais e sociais de determinada (s) sociedade (s).

Alexy (1999, p. 58), ao descrever princípios referentes aos direitos humanos sintetiza que os mesmos possuem "natureza abstrata, pressupondo a ponderação entre os direitos em conflito, sendo necessária a presença do Estado não só como instância de concretização, mas também como instância apta a tomar decisões que efetivem estes direitos humanos”.

Internacionalmente, haveriam dois instrumentos de persecução à defesa dos direitos fundamentais, a saber: o instrumento clássico do contratualismo positivado, à exemplo dos pactos e tratados de direitos humanos; e em um segundo momento, em uma visão neojusnaturalista, a adoção de costumes internacionais com força vinculante a todos, independentemente das respectivas soberanias nacionais e dos contextos culturais em que elas estejam plantadas, a dignidade da pessoa humana não pode criar pessoas de $2^{\circ}$ ou $3^{\circ}$ categoria.

Neste sentido, parte da doutrina internacionalista é assente ao afirmar que as regras de direitos humanos jamais ferem a soberania estatal, muito pelo contrário, a soberania estatal decorre da soberania popular, sendo que as violações aos direitos fundamentais ferem além da soberania estatal, também a soberania popular.

Para os neojusnaturalistas, em não havendo tratados, ou mesmo, em havendo-os, não houver sua ratificação, os direitos fundamentais enquadrariam-se em "jus cogens", decorrentes da base principiológica do direito natural, devendo ser aplicado como elemento supressor de eventuais lacunas, tais normas consuetudinárias, independentemente dos pactos, como exemplificativamente ocorre com o Princípio Internacional da Não Devolução para Refugiados.

Segundo parte dos internacionalistas, um dos objetivos do Direito Internacional dos Direitos Humanos, seria a busca de um Constitucionalismo Global, tendente à proteção internacional dos direitos fundamentais, limitando-se o poder do Estado, eis que para estes teóricos os direitos fundamentais não deveriam ser reduzidos ao domínio estatal reservado, vez R. Fac. Dir. UFG, v. 38, n. 1, p. 92 - 118, jan. / jun. 2014 
que se trata de legítimos temas de interesse internacional, justificando o abandono de uma concepção absoluta, "hobbesiana" de soberania, para uma concepção "kantiana", baseada na cidadania universal, hoje chamada também de cidadania cosmopolita.

Quanto à questão sobre a internacionalização dos direitos humanos, é necessário adiantar que este é hoje um dos temas mais ricos em que está envolvida esta questão. Sobre isto preleciona José Augusto Lindgren Alves (1994, p.5), a saber:

As construções internacionais existentes ultrapassaram as noções tradicionais de soberania e interesses. Ao subscrever uma convenção internacional sobre direitos humanos, ao participar de organizações regionais sobre o assunto, ou conforme é hoje interpretação corrente, pelo simples fato de integrar-se às Nações Unidas, para quem a declaração universal dos direitos humanos, se não era originalmente compulsória, tem força de jus cogens como direito costumeiro. Os Estados abdicam soberanamente de uma parcela da soberania, em sentido tradicional, obrigando-se a reconhecer o direito da comunidade internacional de observar e, consequentemente, opinar sobre sua atuação interna, sem contrapartida de vantagens concretas.

Para Guido Soares (2004, p.341), a soberania popular é intrínseca a concepção de um Estado Democrático, o qual possui as seguintes condições indispensáveis:

(a) A soberania baseada na vontade popular; (b) a divisão funcional do poder, com técnica de controle de seu exercício e, sobretudo, (c) a proteção dos direitos humanos, estes de início, configurados em documentos separados, conquanto integrados na organização constitucional dos Estados e, na sequência histórica, como partes constitutivas dos próprios textos das Constituições.

Com visão internacionalista, discorre-nos acerca da aplicabilidade dos costumes internacionais em matéria de direitos humanos, Flávia Piovesan (2006, p. 36):

Quanto ao costume internacional, sua existência depende: a) da concordância de um número significativo de Estados com relação a determinada prática e do exercício uniforme relativo a ela; b) da continuidade de tal prática por considerável período de tempo já que o elemento temporal é indicativo da generalidade e consistência de determinada prática; c) da concepção de que tal prática é requerida pela ordem internacional e aceita como lei, ou seja, de que haja o sendo de obrigação legal, a opinio juris. Atente-se ao fato de que o costume internacional tem eficácia erga omnes, aplicando-se a todos os Estados, diversamente dos Tratados Internacionais que só se aplicam aos Estados que os tenham ratificado.

Diante disto, os costumes internacionais constituem uma preciosa ferramenta de relativização ao conceito clássico de soberania, visto que possuindo um caráter elástico, amoldam-se facilmente às situações concretas existentes no contexto dos direitos humanos. 
Mas, ainda vale a pena discorrer um pouco mais sobre a questão da internacionalização dos direitos humanos. Embora o Direito Internacional dos Direitos Humanos constitua um movimento relativamente recente, ele começa a desenvolver-se no pensamento jurídico-constitucional do pós-guerra, sendo neste contexto da verificação e lembrança das atrocidades nazistas que surgirá um referencial ético que passará a orientar a ordem internacional.

Isto se dará em diversos campos, no político, no econômico, no cultural etc., e, como referência fundamental, também e necessariamente no campo jurídico. A resposta jurídica, se dará pela via dos Tratados Internacionais, tendo como ponto de mira o conjunto dos direitos do homem. Estes Tratados, ao mesmo tempo que vão comprometer os Estados na luta pela causa dos direitos, serão também "agraciados" com a atribuição de funções dirigidas à incorporação em suas legislações internas (Constituições) e à implementação e defesa de todos os direitos do homem. Uma forte alavanca estará à disposição das ações de defesa: Tribunais e Cortes internacionais sempre atentos e dispostos a "el ejercicio de la función judicial internacional", como Cançado Trindade intitula o seu livro sobre as "Memorias de la Corte Interamericana de Derechos Humanos". (vide bibliografia final)

A relação que se estabelece ao redor do tema direitos humanos é muito forte quando se analisam o Direito Internacional e o Direito interno, o constitucionalismo (como processo) internacional e os constitucionalismos nacionais, com muitos pontos confluentes, havendo a cada dia mais, uma comunicação permanente entre eles. É isto que faz "sustentar que o ser humano é sujeito tanto do direito interno quanto do direito internacional, dotado em ambos de personalidade e capacidades jurídicas próprias" (Cançado Trindade, na apresentação de Piovesan, 1997, p.19), sendo neste sentido que trabalhamos que os direitos humanos possuem natureza universal.

Eis aí o processo de internacionalização dos direitos humanos que, além de ter permitido a formação de um sistema normativo internacional de proteção destes direitos, trouxe à cena, além do Estado, novos atores que passaram a participar da arena internacional, tais como os indivíduos e as organizações não-governamentais, que, no seu conjunto, compõem a "sociedade 
civil internacional". Com ela se defronta a comunidade política internacional e o clássico poder soberano, mesmo que decadente, dos Estados nacionais.

Portanto, voltando, na atualidade, os principais desafios para a implementação internacional na seara dos direitos humanos, são a crença na soberania aliada ao princípio absolutista da não ingerência, bem como a globalização e seus efeitos notadamente às diferenças e assimetrias abissais de desenvolvimento, além da incorporação mercadológica dos Estados.

Nos ensinamentos de Bobbio (2004), a eficácia e a garantia dos aludidos direitos humanos na esfera global "somente será implementada quando uma jurisdição internacional se impuser concretamente sobre jurisdições nacionais, deixando de operar dentro dos Estados, mas contra os Estados e em defesa dos cidadãos".

Desta forma, quanto aos efeitos dos supraditos direitos, operam-se "erga omnes", vinculando Estados, tornando-se tormentosa a questão no que tange à soberania dos mesmos, visto que, em se tratando de direitos humanos, há uma ruptura com a tradição positivada contratual.

Assim, logicamente, em havendo tratados acerca da defesa de tais direitos, o contratualismo positivado é imperativo, sendo que em matéria de direito internacional, vem ganhando força a doutrina na qual em se tratando de direitos humanos, as normas, mesmo que lastreadas nos costumes, são cogentes, de eficácia absoluta, não devendo preponderar quaisquer restrições, mormente aquelas revestidas sob o manto da soberania.

Nestes termos, haveria a internacionalização do Direito Constitucional, pugnando por um constitucionalismo aberto. Segundo Piovesan (2002, p. 59):

O processo de internacionalização dos direitos humanos traz reflexos no âmbito normativo interno, na medida em que as Constituições contemporâneas hão de respeitar parâmetros internacionais mínimos voltados à proteção da dignidade humana, convertida em pressuposto ineliminável de todos os constitucionalismos. 
Trata-se de uma dimensão multinacional que exige a formulação de uma jurisdição constitucional transnacional, universal.

Neste particular, Canotilho (1998, p. 1217) por sua vez preceitua que:

A globalização das comunicações e informações e a 'expansão mundial' de unidades organizativas internacionais, privadas ou públicas, deslocam o papel obsidiante do 'ator estatal', tornando as fronteiras cada vez mais irrelevantes e a interdependência política econômica cada vez mais estruturante.[...] O dogma do Direito Constitucional centrado no Estado e na soberania estatal tende a fragilizar-se. A internacionalização e a 'marcosualização' tornam evidente a transformação das ordens jurídicas nacionais em ordens jurídicas parciais, nas quais as Constituições são relegadas para um plano mais modesto de 'leis fundamentais regionais'. Mesmo que as Constituições continuem a ser simbolicamente a magna carta da identidade nacional, a sua força normativa terá parcialmente de ceder perante novos fenótipos político-organizatórios e adequar-se no plano político e no plano normativo aos esquemas regulativos das novas associações abertas de Estados nacionais abertos.

Acerca da ideologia globalizante presente na universalização dos direitos humanos, Tavares (2009, p. 430) ressalta a existência de uma forma de dominação cultural mascarada pelo ideário de movimento, de processo evolutivo, a saber:

\begin{abstract}
Para os cultores da teoria da universalização atrelada ao gênero humano, determinada comunidade adota valores diversos, porquanto o seu nível de desenvolvimento cultural e racial não foi o suficiente para perceber o anacronismo, o irracionalismo de seus valores. Em outras palavras, tal comunidade ainda não alcançou o nível necessário para vislumbrar "a verdade". Com efeito, de acordo com essa teoria, os indivíduos que adotam valores diversos são considerados intelectualmente imberbes, como se de "bons selvagens" se tratasse. E, a si próprios, os encampadores dos direitos humanos universalizáveis se mostram como curadores, os catequizadores, capazes de apresentar a ideia de civilização (superior) aos incultos.
\end{abstract}

Frente a este viés cultural ideológico, torna-se imprescindível a adoção de um constitucionalismo global tendente à universalização compartilhada, respeitando as diferenças e as culturas entre os povos, uma universalização horizontal onde não existam "senhores da verdade cultural e científica".

A universalização compartilhada traduz o fundamento de uma nova estatalidade, de uma nova supranacionalidade, de forma que este compartilhamento seja realizado em um ambiente de abertura e cooperação entre os Estados, não havendo espaço à sobreposição de uns sobre outros. 
Isto se faz necessário segundo Aguado (2012, p. 53), eis que:

O Estado por si só, não tem mais a capacidade de intervir nos "agressivos" processos globais e mesmo regionais... Esta capacidade não se refere unicamente ao campo político ou econômico, refere-se também ao jurídico-constitucional, pois a supraconstitucionalidade está inserida no desenvolvimento da supranacionalidade.

Diante disso, a materialização destes objetivos protetivo-humanitários somente ocorrerá com o aprofundamento compartilhado de uma Corte Internacional de Direitos Humanos com eficácia jurídica supranacional, moral e econômica, sancionando Estados e pessoas cuja tirania e absolutismo afrontam os direitos humanos de seus nacionais ou estrangeiros que em seu território se encontrem.

\section{A Realidade Internacional: os Deslocamentos de Africanos à Europa}

Como real consequência da globalização reversa ou colonização às avessas, verificamos a entrada maciça de africanos na Europa, de latinos nos Estados Unidos, haitianos no Brasil, enfim, pessoas que abandonam seus territórios em razão da inexistência de recursos naturais, trabalho e alimentos, ausências materiais que tornam a vida muito difícil em seus locais de origem, impossibilitando-lhes um mínimo de dignidade humana.

A necessidade de manutenção da vida, bem como a procura por melhores condições e oportunidades, vem forçando estes contingentes à migração forçada ao continente europeu e à América do Norte, ultrapassando a linha abissal do Equador.

Especialmente na Europa, a imigração de africanos apresenta-se como questão emblemática e relevante sob o ponto de vista jurídico-social, afigurada sua natureza eminentemente coletiva acerca da titularidade de direitos consubstanciados na ordem internacional de cunho protetivo ao bem estar humano em sentido lato.

Segundo previsões mais otimistas, as catástrofes naturais e a fome trarão milhões de deslocados para regiões mais estáveis. Para a Prof. Cristina Tirado (2011), da Universidade da Califórnia, segundo projeção feita pela ONU, apenas no que se refere aos deslocamentos ambientais, "Cinquenta milhões de refugiados ambientais se deslocarão para o norte do globo até R. Fac. Dir. UFG, v. 38, n. 1, p. 92 - 118, jan. /jun. 2014 
2020, fugindo da escassez de alimentos provocada pela mudança do clima. Quando as pessoas não vivem em condições sustentáveis, elas migram”.

Pondera Milaré (2009, p.57), quanto ao aumento significativo na velocidade das alterações naturais e suas consequências na atualidade:

As implicações ambientais de certa forma avançam sobre os continentes rapidamente, incrementadas por atividades humanas que dilapidam patrimônios biológicos formados no decorrer de tempos geológicos, com processos irreversíveis tendentes ao esgotamento, acentuando o desequilíbrio ecológico.

Trata-se de instabilidades naturais agravadas pelas atividades produtivas e sociedade de consumo decorrentes da globalização, acarretando aceleradas transformações, cujos efeitos devastadores determinam a mobilização de grandes fluxos populacionais para territórios de outros Estados.

Desde há tempos, já presenciamos a entrada maciça de africanos ao sul do continente europeu, os quais ilegalmente atravessam o Estreito de Gibraltar ou o mar Mediterrâneo, sendo provenientes da região do Sahel, área de transição climática cujo processo de desertificação vem agravando-se rapidamente pela ação humana.

Geograficamente, durante muito tempo, o Sahel, localizado ao sul do deserto do Sahara, onde atualmente se localizam países como Chade e Sudão, possibilitava um mínimo existencial aos povos que ali viviam, eis que em sendo área de transição entre o deserto e regiões equatoriais mais nobres, possuía vegetação com importante função ambiental de barreira, impedindo a desertificação do sul do continente, além de possuir vários rios e cursos de água vitais às populações locais.

Com a desenfreada exploração carvoeira, bem como o uso indiscriminado de técnicas agrícolas rudimentares como a coivara (uso do fogo para limpeza do terreno) e a monocultura agroexportadora presente na globalização do campo, extirparam-se quase todas as vegetações naturais ali presentes, possibilitando o assoreando dos rios e a seca de nascentes, desertificandose áreas outrora férteis, gerando fome e miséria, forçando a saída de levas de deslocados para a Europa, notadamente Espanha e Itália, onde pleiteiam melhores condições de vida. 
Segundo o IICA - Instituto Interamericano de Cooperação para a Agricultura, o problema não é antigo:

Foi somente no início dos anos 70, quando ocorreu uma grande seca na região localizada abaixo do deserto do Sahara, conhecida como Sahel, onde mais de 500.000 pessoas morreram de fome, que a comunidade internacional reconheceu o impacto econômico, social e ambiental do problema, estabelecendo um programa mundial de ação para combater a desertificação.

Entretanto, perante a crise econômica instalada em muitos países da União Européia, conceitos como nacionalismo e soberania ganham força, mitigando de certa forma a adoção de um sistema misto, isto é, híbrido, cujas normas atinentes à dignidade da pessoa humana ou mesmo os costumes internacionais, acabariam suprindo lacunas, integrando-se ao direito dos países com força constitucional.

Sob a ótica constitucionalista global, acerca do princípio da dignidade da pessoa humana, descreve José Afonso da Silva (2001, p. 90):

Tal princípio é o atributo intrínseco, da essência da pessoa humana, único ser que compreende um valor interno, superior a qualquer preço, que não admite a substituição equivalente. Assim, a dignidade entranha e se confunde com o próprio ser humano. Por isso é que a pessoa é um centro de imputação jurídica, porque o Direito existe em função dela e para propiciar seu desenvolvimento.

Por essas razões, a dignidade da pessoa humana via jusnaturalismo, insere-se como princípio constitucional de importância essencial a qualquer ordenamento, atrelando e nele decorrendo todos os demais regramentos jurídicos internacionais, possibilitando ensejar a obrigação dos Estados quanto à promoção da boa existência e defesa destes direitos fundamentais.

Sobre a proteção dispensada aos estrangeiros pelos respectivos Estados, relata Rezek (2007, p. 194):

Qualquer estrangeiro encontrável em seu território - mesmo que na mais fugaz das situações, na zona de trânsito de um aeroporto - deve o Estado proporcionar a garantia de certos direitos elementares da pessoa humana: a vida, a integridade física, a prerrogativa eventual de peticionar administrativamente ou requerer em juízo, o tratamento isonômico em relação a pessoas de idêntico estatuto. 
Internacionalmente, segundo o ACIDI- Alto Comissariado para a Imigração e Diálogo Intercultural, mediante dados fornecidos pelo Observatório de Imigração da EUROSTAT, os contingentes deslocados avançam rapidamente:

No segundo trimestre de 2011, tomando como base os dados fornecidos pelos Ministérios do Interior de cada um dos Estados Membros da União Européia e pelos organismos oficiais competentes, dá conta de um considerável aumento de pedido de asilo neste período, atingindo-se um total de 69 mil pedidos que representam um aumento de 12.800 pedidos (23\%) face ao valor registrado no mesmo trimestre do ano anterior. Tal aumento pode ser explicado por via das crises sociais e políticas vividas em diversos países no norte de África, verificando-se que o maior aumento de pedidos, por nacionalidades, se verifica entre tunisinos e líbios. Dada a proximidade geográfica, o número de pedidos apresentados em Malta aumentou 56 vezes.

Quanto ao destino dos contingentes africanos pressionados por ocorrências ambientais e humanas, revelam as pesquisas do Observatório de Imigração Europeu EUROSTAT, disponíveis no site da ACIDI, que "a lista de países de destino é encabeçada pela França, a Alemanha e a Bélgica, países que juntos concederam cerca de metade das respostas positivas dadas em toda União Européia”.

Neste sentido, segundo os dados do Eurostat - Alto Comissariado para a Imigração e Diálogo Internacional de Portugal para o ACIDI:

O Eurostat, gabinete de estatística da União Européia, acaba de lançar uma publicação intitulada "Migrants in Europe - A statistical portrait of the first and second generation", que compila um importante conjunto de informações estatísticas de caráter socioeconômico sobre os imigrantes residentes no espaço comunitário, observando-se aspectos como os seguintes: a taxa de desemprego, em 2008, no escalão 25-64 anos era de $10 \%$ para os nascidos no estrangeiro contra $6 \%$ para os nativos; $31 \%$ das pessoas nascidas no estrangeiro encontravam-se, nesse mesmo ano, em risco de pobreza ou de exclusão social, quando a porcentagem para a população nativa era de $20 \%$; e o primeiro grupo enfrentava também piores condições de habitabilidade. Em Portugal, as taxas não eram diferentes: taxa de desemprego $9 \%$ contra $7 \%$; taxa de sobrequalificação $25 \%$ contra $14 \%$; taxa de risco de pobreza $26 \%$ contra $22 \%$ e taxa de sobrelotação dos alojamentos $23 \%$ contra $15 \%$.

Segundo informações da UNRIC - Centro Regional de Informações das Nações Unidas, a ONU, em meados de 2006, pronunciou-se acerca das migrações internacionais, tendo discursado Kofi Annan quando da entrega de referido relatório:

Estamos mesmo no meio de uma nova era de migrações, que representam atualmente um "fenômeno mundial". Os abusos a que muitos migrantes são sujeitos, quer em trânsito, quando ficam à mercê de contrabandistas e traficantes, o que, por vezes tem conseqüências fatais, quer nos países onde se instalam, onde são, com frequiência, 
explorados por empregadores sem escrúpulos e vítimas de reações xenófobas por parte de certos grupos da população e, em alguns casos, de representantes da autoridade pública. Da mesma forma, não podemos deixar de ter consciência das tensões sociais e culturais que surgiram em muitos países, onde se fixaram recentemente grandes grupos populacionais de origem estrangeira, particularmente quando estes tem tradições ou crenças que diferem consideravelmente daquelas a que os residentes de longa data no país estão habituados.

Desta forma, a própria ONU reconhece as diferenças culturais e sociais existentes entre nativos e imigrantes, notadamente africanos. Tais diferenças resultam em essência, do "modus vivendi", da religião, das tradições e culturas, possibilitando-se o surgimento de um convívio não harmonioso, tal qual vem ocorrendo na França, com as revoltas dos povos muçulmanos contra leis que impedem o uso de vestimentas como a burca, nas escolas públicas, bem como a xenofobia e o renascimento de grupos neonazistas na Alemanha, skinheads, dentre outros.

A respeito das discussões internacionais sobre xenofobia e discriminação racial, as quais estão presentes no contexto imigratório, destaca-nos Lucas Lehfeld (2012, p. 415-433):

Em abril de 2009, por exemplo, reafirmou-se a Declaração e programa de ação assinados na III Conferência Mundial contra o racismo, a xenofobia, a discriminação racial e intolerância correlata, realizada na cidade de Durban, na África do Sul, de 31.08.2001 a 07.09.2001, momento histórico na luta contra o sistema institucionalizado do apartheid na África do Sul, e promoção da busca pela igualdade racial na comunidade internacional. Embora sem ter caráter normativo interno, o país vem participando efetivamente das rodadas de discussão e reafirmação da referida declaração, o que demonstra uma preocupação da comunidade internacional quanto ao desrespeito e intolerância decorrentes do racismo, da discriminação racial e xenofobia.

Em realidade, a soberania "fechada" dos Estados desenvolvidos europeus acaba conduzindo a uma blindagem étnica, social e cultural, sendo que politicamente, verifica-se a crescente popularidade de candidatos contrários à entrada de estrangeiros. A adoção de um critério integrativo fulcrado em normas consuetudinárias internacionais humanistas, objetivadas pela persecução à dignidade da pessoa humana, possibilitariam, não fosse a força das questões político-econômicas, culturais e ideológicas envolvidas, uma efetiva integração destes contingentes humanos excluídos de um mínimo existencial.

\section{Conclusões}


Os direitos humanos na órbita internacional, em decorrência da dignidade da pessoa humana, são universais, isto é, válidos para todos, independentemente de ordenamentos jurídicos regionais e "dogmas" presentes no ideário da soberania. Tais direitos revestem-se do manto da indivisibilidade, cuja garantia é a condição para a observância dos demais direitos, sendo que quando um deles é violado, todos os demais assim o são. Os direitos do homem, no seu conjunto, formam algo indivisível, além de ser um bem igualmente válido para todos.

A base axiológica destes direitos encontra-se insculpida junto ao art $5^{\circ}$, da Declaração de Viena de 1993, assegurando que todos os direitos humanos são universais, indivisíveis, interdependentes e inter-relacionados, visto que a comunidade internacional deve tratar estes direitos globalmente, de maneira justa e equitativa, em pé de igualdade e com a mesma ênfase.

Desta forma, a teoria humanitária internacionalista, aplicável à problemática dos estrangeiros excluídos, defende que os direitos humanos são dotados da constituição de normas cogentes de ordem pública internacional, voltadas para um interesse geral, transcendendo interesses particulares meramente contratualistas, manifestando repúdio a qualquer ordenamento jurídico indiferente a estes valores, bem como qualquer tentativa de fragmentação, regionalização, tendendo à diminuição do absolutismo contido no ideário da soberania estatal.

Portanto, há um tormentoso conflito entre a soberania e o direito internacional dos direitos humanos, haja vista que este último possui um caráter elástico, limitando o poder estatal mediante a criação de aparatos internacionais de proteção destes direitos, como a adoção dos costumes internacionais. Tais normas consuetudinárias, que existem em um número significativo de Estados, via prática uniforme de atos por um considerável período de tempo, acabam assumindo os contornos de uma obrigação moral internacional, com força de obrigação legal “opinio juris" e com eficácia "erga omnes", ou seja, difusa, atingindo desta forma todos os Estados.

Nesta linha de raciocínio proveniente da doutrina internacionalista humanitária, propõe-se juridicamente a afirmação de que as regras de direitos humanos jamais ferem a soberania estatal, muito pelo contrário, a soberania estatal decorre da soberania popular, sendo R. Fac. Dir. UFG, v. 38, n. 1, p. 92 - 118, jan. / jun. 2014 
que as violações aos direitos humanos ferem a própria soberania popular em um contexto difuso, já que violam os direitos mais preciosos da espécie humana, violando em decorrência a própria soberania estatal. Daí a necessidade de uma soberania flexível aos direitos humanos, cuja envergadura assenta-se sobre a importância de uma soberania humana e não sobre uma soberania estatal vinculada ao ideal globalizante, consoante exposto no presente trabalho.

Frente a isto, na órbita mundial, postulando pela real eficácia e efetividade dos direitos humanos, torna-se necessária a adoção de um diálogo intercivilizatório e multicultural para o cumprimento de preceitos básicos pelos Estados, tais como o respeito às diversidades, não utilização de violência e a transposição interna de normas universais, intrínsecas aos direitos humanos, válidos independentemente de qualquer tempo e lugar.

A proposta do multiculturalismo, através de suas políticas sociais de acolhimento, busca a proteção e consequentes reivindicações de grupos excluídos, busca a integração desses grupos, sendo que a pluralidade de culturas, conceito no seu sentido mais amplo, a diversidade de condições de vida e de opções para a mesma e as condições, dia a dia diminuídas, que são oferecidas aos piores situados nos direitos de viver, nos obrigam a entender o intercivilizatório e o multicultural como uma tentativa necessária, de integração e convivência.

Para tanto, a própria ONU deveria ser reformada, seu Conselho de Segurança alargado, possibilitando uma participação mais ampla e democrática, desmilitarizando ações encabeçadas por grandes potências, objetivando a paz e a cooperação internacional, reformas estas improváveis, diante da afigurada resistência política dos membros do conselho, bem como pela forçosa liderança dos EUA (econômica e militar) e a necessidade da mudança em sua estrutura, a qual parece inviável visto a necessidade da aprovação unânime dos membros do Conselho de Segurança.

Desta forma, seria necessária a restauração de uma opinião pública global favorável, ou seja, restaurar a confiança mundial na ONU como organismo competente para manter a paz e a segurança, o que seria inicialmente possível graças à realização de trabalhos de assistência com 
maior autonomia, com orçamentos seguros e independentes, conduzindo a um partilhamento democrático humanitário.

Enfim, necessitamos de uma conceituação global humanitária eficaz e válida para todos, um universalismo jurídico humanista, sem quaisquer entraves reunidos sob o manto da ultrapassada e excludente soberania, principalmente porque normas e costumes que digam respeito aos direitos humanos fundamentais deveriam estar acima deste dogma soberano e absolutista, vinculando Estados ao seu imediato cumprimento e respeito, assegurando a todos a necessária dignidade humana.

\section{Referências Bibliográficas}

ACIDI. Alto Comissariado para a Imigração e Diálogo Intercultural. Disponível em:<http://www.oi.acidi.gov.pt/modules.php?name=News\&file=article \&sid=3205>.Acesso em 21.mai.2012.

AGUADO, Juventino de Castro. A Utopia Supranacional e a Realidade Soberana dos Estados. Ribeirão Preto: Legis Summa, 2012.

ALEXY, Robert. Direitos fundamentais no Estado constitucional democrático. Revista de Direito Administrativo, v. 217, set 1999.

ALVES. José Augusto Lindgren. Os direitos humanos como tema global. São Paulo: Perspectiva, 1994.

BOBBIO, Norberto. A Era dos Direitos. Tradução de Carlos Nelson Coutinho. Rio de Janeiro: Elsevier, 2004.

CANOTILHO, José Joaquim Gomes. Direito Constitucional e Teoria da Constituição. Coimbra: Almedina, 1998.

CAVARZERE, Thelma Thais. Direito Internacional da Pessoa Humana: A circulação internacional de pessoas. Rio de Janeiro: Renovar, 1995.

CORTINA, Adela. Ciudadanos del Mundo. 3. ed. Madrid: Alianza Editorial, 2009.

FALK, Richard. Globalização Predatória: Uma Crítica. Tradução Rogério Alves. Lisboa: Instituto Piaget, 1999.

HABERMAS, Jurgen. A Constelação pós-nacional. São Paulo: Littera Mundi, 2001. 
IICA. Instituto Interamericano de Cooperação para a Agricultura. Disponível em: $<$ http://www.iicadesertification.org.br/lendo.php?sessao=oda=>. Acesso em 20.mai.2012.

KELSEN, Hans; CAMPAGNOLO, Umberto. Direito Internacional e Estado Soberano. Tradução Marcela Varejão. São Paulo: Martins Fontes, 2002.

LEHFELD, Lucas de Souza. O sistema de proteção internacional dos direitos dos afrodescendentes. Revista de Direito Constitucional e Internacional. $\mathrm{n}^{\mathbf{0}}$ 78, 2012, p. 415-433.

MILARÉ, Édis. Direito do Ambiente: A gestão ambiental em foco. 6.ed. São Paulo: Revista dos Tribunais, 2009.

PIOVESAN, Flávia. Direitos Humanos, Globalização Econômica e Integração Regional. São Paulo: Max Limonad, 2002.

Direitos Humanos e o Direito Constitucional Internacional. 2.ed. São Paulo: Max Limonad, 1997. 2008.

Direitos Humanos e o Direito Constitucional Internacional. 9.ed. São Paulo: Saraiva,

Direitos Humanos e Justiça Internacional: Um estudo comparativo dos sistemas regionais europeu, interamericano e africano. São Paulo: Saraiva, 2006.

RAMOS, André de Carvalho. Teoria Geral dos Direitos Humanos na Ordem Internacional. 2.ed. São Paulo: Saraiva, 2012.

REZEK, José Francisco. Direito Internacional Público. 10. ed. São Paulo: Saraiva, 2007. SILVA, José Afonso da. Curso de direito constitucional positivo. 20.ed. São Paulo: Malheiros, 2001.

SOARES, Guido Fernando Silva. Curso de Direito Internacional Público. v.1, 2.ed. São Paulo: Atlas, 2004.

TAVARES, André Ramos. Curso de Direito Constitucional. 4. ed. São Paulo: Saraiva, 2009.

TAVARES NETO, José Querino. Diálogo entre culturas: direito a ter direito. Curitiba: Juruá, 2010.

TIRADO, Cristina. 50 Milhões de Refugiados Ambientais em 2020, In MENDONÇA, José Eduardo. 22.fev.2011. Disponível em:< http://planetasustentavel.abril.com.br/blog/planetaurgente/50-milhoes-refugiados-ambientais-2020-282666>. Acesso em 21.mai.2012.

TRINDADE, Antônio Augusto Cançado. El ejercicio de la función judicial internacional: Memorias de la Corte Interamericana de Derechos Humanos. Belo Horizonte, Brasil: Del Rey, 2001. 
UNRIC. Centro Regional de Informações das Nações Unidas. Disponível em: < http://www.unric.org/pt/actualidade/2928>. Acesso em 22.mai.2012. 